\title{
Estudo analítico do direito ao cargo.
}

\author{
Fernando Henrique Mendes de Almeida \\ Livre-docente de Direito Administrativo da Faculdade de \\ Direito da Universidade de São Paulo.
}

\begin{abstract}
Súmula: 1. Introdução. 2. Direito ao cargo, na hipótese de estabilidade. 3. Direito ao cargo, na hipótese de vitaliciedade. 4. Criação, modificação e extensão do direito ao cargo. 5. Defesa do direito ao cargo. 6. Observações colhidas da doutrina. 7 . $O$ direito ao cargo no Direito
\end{abstract} Anterior.

\section{Introdução.}

1. De visão panorâmica do pessoal existente nos serviços públicos administrativos diretos, desde logo, colhese a impressão de que todo êle se vincula à Administração Pública através de diversas espécies de relações juridicas de função pública. É o que vem plasmado no sistema estruturado pelo nosso Direito Positivo. A diversidade consiste na possibilidade de distinção entre:

I) relações jurídicas de função pública insuscetíveis de gerar quaisquer garantias para aquêles que, mediante elas, ocupam cargos públicos;

II) relações jurídicas de função pública que não na origem, mas, na sucessão, podem gerar fixidez relativa;

III) relações jurídicas de função pública que, na origem, geram fixidez quase absoluta. As relações jurídicas de função pública situáveis na letra "a" da classificação 
acima referem-se aos casos de confiança e de livrenomeação e livre exoneração de ofício ${ }^{1}$; as situáveis na letra "b" são as de ocupantes de cargos que tendem à conquista da estabilidade, ou já a conquistaram; as situáveis na letra "c" são as de ocupantes de cargos em que, em benefício mesmo do melhor exercício de seus misteres, têm direito ao cargo, sob a garantia da vitaliciedade ${ }^{2}$.

2. Em resumo, só se pode falar de direito ao cargo com respeito a: $1 .^{\circ}$ ) funcionários estáveis; $2 .^{\circ}$ ) funcionários vitalícios ${ }^{3}$.

3. Quando emergido, nas relações jurídicas de função pública, o direito ao cargo não tem natureza patrimonial ${ }^{4}$. Os cargos públicos são criados no interêsse público e não assim no dos que, em virtude de relações jurídicas de função pública, os ocupam. Assim, ainda que, a título de rósea metáfora, não é admissível se aplique à situação dos ocupantes de cargos vitalícios a idéia de propriedade, como

1. Const. Federal de 1946, parágrafo único do art. 188. Alí os constituintes usaram a expressão "livre demissão", esquecidos de que demissão, hoje, é pena (Confira-se o artigo 15, parágrafo $6 .^{\circ}$ da Lei Federal n. ${ }^{\circ}$ 1.711, de 1952). Sôbre a generalização do emprêgo da palavra demissão por exoneração, leia-se: Petrozziello, Rapporto di pubblico impiego p. ce, nota no Trattato Completo, de V. E. ORLANDo.

2. Para o âmbito dêste estudo, no artigo 187 da Constituição Federal de 1947 só apresentam interêsse os Ministros do Tribunal de Contas e os professôres catedráticos. Os órgãos do Judiciário e os ofícios de Justiça fogem a êle.

3. Constituição Federal de 1946: artigos 188 e 189. A perda de cargo, para os estáveis, ocorre em virtude de imposição de pena disciplinar fundada, de caráter expulsivo (C. Federal de 1946: artigo 190) ou de pena acessória de perda de função pública (Código Penal, artigo 67, n. ${ }^{\circ}$ I); para os vitalícios, só em decorrência de sentença passada em julgado, que lhes comine tal pena (Constituição Federal de 1946, artigo 189, n. ${ }^{\circ}$ I).

4. MaSaGão, Curso de Direito Administrativo, II, n. 379, p. 232. 
até ao comêço do século era corrente ${ }^{5}$, ainda que ao provimento haja precedido concurso ${ }^{6}$.

4. O direito ao cargo é pessoal e se concretiza através do regular exercício das atribuições, com o cumprimento do dever de comparência ${ }^{7}$ a cuja verificação corresponde a percepção do estipêndio que, por lei, couber.

5. Quem é titular do cargo público e já tenha direito ao cargo, extinto êste, é disponibilizado. Tal é o sentido que se deve ter presente na expressão da lei: "a estabilidade diz respeito ao serviço público e não ao cargo"8 a menos que se pudesse admitir colisão de textos estatutários com textos constitucionais. Com ef eito, se a Constituição Federal alude a perda de cargo ${ }^{9}$ e só se pode perder o que já se teve, inútil é que um estatuto se ponha em sutilezas.

5. A expressão "lente proprietário" aparece transcrita várias vêzes, (como, por ex., na p. 374) na obra de Primitivo MoAcYr: $A$ instrução e o Império. - Era freqüente nos escritores antigos, como se vê em Silvestre Gomes DE Morais, Tractatus de executionibus instrumentorum et sententiarum, tomo II, cap. 3 , n.os 19 a 25 e p. 36 a 37 .

6. Pela Ordenação Fìlipina do livro $10^{\circ}$, título XCVI, conclui-se que os ofícios de Justiça e de Fazenda eram dados pelo Rei a seus afetos; mas, êle podia tirá-los, como os dera, sem ser obrigado a satisfação alguma. Parece ter vindo daí a idéia de "propriedade de cargo público".

7. Lei Federal n. ${ }^{\circ}$ 1.711, de 1952, artigo 194, n. ${ }^{\circ}$ s. I e II.

8. Lei Federal n. ${ }^{\circ} 1.711$, de 1952 , artigo 82, parágrafo $2 .^{\circ}$.

9. Const. Federal de 1946, artigo 189:

.... perderão o cargo:

II) quando estáveis .. (no caso)... de serem demitidos.

Inútil é que o artigo 82 da Lei Federal n. ${ }^{\circ} 1.711$, de 1952, no parágrafo $2 .^{\circ}$ queira distinguir a estabilidade (que é grau de direito ao cargo) em estabilidade no serviço, para o efeito de extinto o cargo, fundar a disponibilização, e em estabilidade no cargo. Trata-se de ociosidade. 
6. A colocação em disponibilidade se impõe, quando o funcionário já é estável, não para significar que não há um direito ao cargo, mas, para fazer crer que, em caso de extinção legal, há, apenas, quando muito, perda transitória do cargo $^{10}$ e não do direito a êle, que êste se transforma em direito ao estipêndio sem correlativo dever de comparência, até a restauração do "statu quo ante".

Realmente. A disponibilização, trazendo em si uma como dispensa de exercício, não tem ef eito suspensivo sôbre a relação de função pública; transforma-a, apenas, de modo provisório porque o cargo não mais existe e "ad impossibilia nemo tenetur". Fica, entretanto, o disponibilizado com os mesmos direitos e deveres de funcionário, guardadas as proporções da natureza das cousas. Assim é que o disponível não pode acumular proventos de outro car'go aos daquele que teve, nem fica isento de sofrer pena disciplinar por faltas cometidas antes de sua disponibilização ${ }^{11}$.

2. Direito ao cargo e suas notas na hipótese de estabilidade.

7. Na hipótese de estabilidade, o direito ao cargo não aparece desde logo, isto é, com a simples nomeação, seguida de investidura, posse e exercício; antes atravessa um periodo de apuração dos integrados nas relações jurídicas de função pública, do qual pode emergir, ou determinar fim das ditas relações jurídicas, embora sem causa oriunda de qualquer espécie de procedimento disciplinar administrativo.

8. Aos diferentes pontos iniciais da conquista da estabilidade nas relações juridicas de função pública não

10. Const. Federal de 1946, art. 189, n..$^{\circ}$ II e parágrafo único Art. 189, n.o II: ... "perderão o cargo": — quando estáveis.... no caso de se extinguir o cargo"... "até o seu obrigatório aproveitamento em outro cargo de natureza e vencimentos compatíveis com o que ocupava".

11. Lei Federal n. ${ }^{\circ} 1.711$, de 1952, artigo 212. 
se tem, na prática entre nós, dado interpretações consentâneas com as características que apresentam. Daí correrem como pacíficas idéias abstrusas que se apoiam na redação nem sempre feliz de estatutos de funcionários públicos, ou no comodismo de soluções jurisprudenciais nem sempre refletidas. É o que veremos, a seguir.

9. Declara a lei que a nomeação será feita "em caráter efetivo", quando se tratar de cargo isolado ou cargo de carreira $^{12}$.

Por tais dizeres ("em caráter efetivo") só se pode concluir que tôda nomeação dá, desde logo, origem a direito ao cargo, ou, por outras palavras, que a "efetivação" é contemporânea da nomeação. Ora, isto é absurdo, porque: $\left.1 .^{\circ}\right)$ nomeação, sem investidura, nem posse, não assinala início de relação de função pública e a própria lei declara que a estabilidade sobrevem em tempo muito distante dela $^{13} ; 2 .^{\circ}$ ) nomeação não seguida de investidura, posse, compromisso de fidelidade e exercício é nenhuma ${ }^{14} ; 3 .^{\circ}$ ) a estabilidade não nasce com a nomeação, por isso que o "funcionário ocupante de cargo de provimento efetivo" sòmente a adquire com 2 ou 5 anos de exercício"15. Como se vê, uma desordem de idéias! $\mathrm{E}$ tudo porque o legislador federal usou a expressão "em caráter efetivo"16 para indicar a idéia de nomeação para cargo em que é possível provimento definitivo futuro, isto é, ocupação com vinculação, dotada de estabilidade, de cargo de provimento efetivo ${ }^{17}$. Mas, o tratar-se de cargo legalmente ocupável em caráter efetivo não autoriza se diga que a nomeação de quem o ocupe seja em "caráter efetivo"18, antes de verificado o

12. Lei Federal n..$^{\circ} 1.711$, de 1952, n. ${ }^{\circ}$ II do art. 12.

13. Lei Federal n..$^{\circ} 1.711$, de 1952, art. 21 , n. ${ }^{\circ}$ II.

14. Lei Federal n..$^{\circ} 1.711$, de 1952, art. 21 , n. ${ }^{\circ}$ II.

15. Lei Federal n. ${ }^{\circ} 1.711$, de 1952 , arts. 29 e 30 .

16. Lei Federal n.० 1.711, de 1952, art. 21, n. ${ }^{\circ}$ II.

17. Lei Federal n. ${ }^{\circ} 1.711$, de 1952, art. 82.

18. Lei Federal n..$^{\circ} 1.711$, de 1952, art. 12, n.o II. 
momento da aquisição da estabilidade, que é, realmente, o instante da efetivação.

A impropriedade, que acabamos de apontar, bem como outras que os estatutos encerram desde o Decreto-lei federal $\mathrm{n}^{\circ}$ 1.713, de 1939 , tem determinado soluções cuja tragicomicidade nos abstemos de comentar.

Não há, em hipótese, qualquer em que o titular possa vir a adquirir estabilidade, admissibilidade lógica de "nomeação em caráter efetivo"19. O que há - isto sim - é nomeação que pode levar o nomeado à estabilidade, no momento em que, então, se assinala a "efetivação".

10. As espécies que podem conduzir, ou deixar de conduzir algum ocupante à conquista da estabilidade são, nas nossas leis, duas: 1. $^{a}$ ) a da relação jurídica de função pública condicionada; $2^{a}$ ) a da relação jurídica de função pública subordinada a têrmo. Na primeira, a lei estabelece um período de prova dentro no qual o ocupante deve preencher requisitos ou, não os preenchendo, ser exonerado de ofício: é o caso de estágio probatório ${ }^{20}$; na segunda, a lei estabelece um têrmo fixo (com "dies a quo" e "ad quem") para a relação de função pública, o qual, excedendo de 2 anos, sem sujeição do ocupante a concurso de que saia classificado e nomeado ${ }^{21}$ passa a ser exonerável ao nuto de Administração Pública. O estagiário, durante o período de prova ou estágio probatório e o interino, dentro do têrmo de dois anos, embora não tenham estabilidade, não podem ser exonerados de ofício, pois, submetê-los a isso é obstrução da conquista da estabilidade ${ }^{22}$.

19. Como se lê no n. ${ }^{\circ}$ II do art. 12 da Lei Federal n. ${ }^{\circ} 1.711$, de 1952.

20. Lei Federal n.0 1.711, de 1952, art. 15 e 82.

21. Lei Federal n..$^{\circ} 1.711$, de 1952, art. 12, n..$^{\circ}$ e parág. $10^{\circ}$

22. Sôbre o assunto, vejam-se: nosso trabalho Notas sôbre o estágio probatório, (Rev. dos Tribunais), vol. 289, 1959, p. 7 a 16 e Revista de Direito Administrativo, vol. 58, 1959; PETrozzIELLo, ob. cit., p. 201; PaCinotT, L'impiego nelle Pubbliche Amministrazioni secondo il Diritto Positivo Italiano, p. $178,{ }^{\circ}{ }^{38}$; PoRTA, Il servizio di prova negli impieghi 
1. Do atẻ aqui exposto, segue-se que, salvo os casos de comissão $o^{23}$ que importam garantia nenhuma: a) o estagiário pode vir a conquistar a estabilidade e, por isto, é inexorável de-ofício, enquanto não se exaure o período de prova; b) o interino, nos dois primeiros anos que antecedem a previsível abertura de concurso, por igual, é inexorável de ofício ${ }^{24}$.

3. Direito ao cargo e as suas notas na hipótese de vitaliciedade.

12. É a vitaliciedade um grau de direito ao cargo. Apresenta-se com maior firmidão do que a estabilidade, por isso que o titular de cargo provido em caráter vitalício sòmente pode ser dêle demitido por fôrça de determinação de sentença passada em julgado ${ }^{25}$.

A vitaliciedade, salvo disposição expressa de lei específica, nasce com a nomeação regular, seguida de investidura, posse e exercício. Adquirida a vitaliciedade contemporâneamente aos fatos que acabámos de assinalar, ela só se elimina: a) pelo julgamento definitivo do titular do cargo; ou, b) pela morte do titular do cargo. Ainda que extinto o cargo, o seu respectivo titular não fica em virtude disto impedido de perceber estipêndio, contar tempo e fruir vantagens, como se extinção não tenha havido ${ }^{26}$.

statali e la sua valutazione, (Riv. di Diritto Pubblico, 1937, 1. ${ }^{\text {a }}$ parte, p. 607 e 609) ; Borazio, Il periodo di prova, na Riv. di Diritto Pubblico, 1924 , p. 360 a 364 .

23. Lei Federal n. 1.711 , de 1952 , parág. $10^{\circ}$ do art. 82 ; Const. Federal de 1946, art. 188.

24. Se o cargo em que ocorre o período de prova é extinto, cabe a exoneração (Const. Fed. de 1946: art. 188, ns. I e II e 189, n. ${ }^{\circ}$ II) $\mathbf{E}$ mesmo quanto ao interino. $\mathbb{A}$ demissão de estagiários e interinos não é de mister preceder procedimento administrativo disciplinar ( $C$. Fed. de 1946: art. 189, n. ${ }^{\circ}$ II).

25. Constituição Federal de 1936: art. 189, n. I.

26. MASAGÃo, ob. cit., lug. cit.. 
A vitaliciedade, pôsto que se comunique ao titular, não é estabelecida, em princípio, em benefício do titular do cargo, e, sim, para que, a salvo de temores e a cavaleiro das seduções da subserviência, possa exercer seus misteres ${ }^{27}$. E o caso dos Ministros do Tribunal de Contas que, sendo funcionários do Executivo, são vitalícios. Êles são vitalícios, mas não são juízes. Nem são juízes porque levam os nomes de Ministros. São vitalícios para que, a salvo de perseguições eventuais, possam examinar a legalidade das Contas do Poder Executivo.

4. Criação, modificação e extinção do direito ao cargo.

13. Todo direito nasce de um ato ou um fato jurídico. $\mathrm{O}$ direito ao cargo, em casos de vitaliciedade, nasce com a nomeação regular, seguida de investidura, posse e exercício. $O$ direito ao cargo, em casos de estabilidade, nasce com o ato ratificador da nomeação anterior, na relação jurídica de função pública sujeita a condição, ou a têrmo, desde que êste seja certo $^{28}$.

A relação de função pública tem seu instrumento na nomeação (ato jurídico-administrativo) que:

a) cria desde logo o direito ao cargo, no caso de vitaliciedade;

b) depende de ratificação posterior ao período de prova, para fazer surgir o direito ao cargo.

14. O direito ao cargo modifica-se por via de: $1^{\circ}$ ) transmutação; $2^{\circ}$ ) transferência; $3 .^{\circ}$ ) remoção.

15. Dá-se a transmutação, quando é extinto o cargo, e o funcionário é disponibilizado até que o recriem, ou

27. Barbalmo, Const. Fed. de 1891, Comentários, $1 .^{\text {a }}$ ed., p. 231, 360 e 361 .

28. Lei Fed. n. 1.711 , de 1952, arts. 12, 15, 17 e 82. 
criem outro cargo análogo àquêle que, estável, ou vitalício. ocupava ${ }^{29}$, contando tempo como se em trabalho estivesse e percebendo estipêndio. $O$ direito se transmuda aí, para singularizar-se nisto: relação jurídica de função pública de quem já não tem cargo. O disponibilizado, ao que nos parece, não é inativo pròpriamente e sim "inativo ficto" 30 . Colocado num quadro suplementar, por obra do que (como lei), embora previsível mas, por êle insuscetível de ser evitada, veio golpear a existência do cargo, o disponibilizado flui de obra do acaso na figura do "fait du Prince"; êle nâo pode ter exercício no espaço e, porque seu cargo não mais existe e já era estável quando foi extinto, seu direito, "si et in quantum", fica restrito ao estipêndio e à contagem de tempo (até ao aproveitamento, se se tratar de estável) e ao estipêndio, à contagem e às prerrogativas ligadas ao cargo extinto (até recriação, se se tratar de vitalício).

16. Modifica-se o direito ao cargo, como dissemos, ainda através da transferência e da remoção. Transferência é a passagem do ocupante de um cargo para outro, em quadros ou unidades diferentes, desde que o provimento seja idêntico ao do cargo primitivo ${ }^{31}$. Há dois tipos de transferência: a) a que corresponde a pedido do funcionário, mas deve nisto levar em conta a conveniência do serviço público ${ }^{32}$; b) a feita no interêsse da Ad. Pública, de ofício $^{33}$. A primeira espécie pressupõe cargo a ser provido por merecimento ${ }^{34}$. A remoção ocorre num mesmo Ministério; não é, pois, tão extensa quanto a transferência, mas,

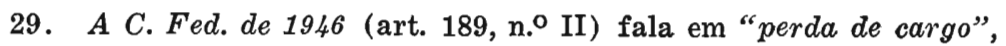
à falta de expressão mais ao alcance do vulgo. O cargo é que é extinto e, por não se poder exercer o que não existe, há a disponibilização.

30. Veja-se, contudo, o art. 212 da Lei Federal n. ${ }^{\circ} 1.711$, de 1952.

31. Lei Federal n. ${ }^{\circ}$ 1.711, de 1952, art. 53.

32. Lei Federal n..$^{\circ} 1.711$, de 1952 , art. 52, n. ${ }^{\circ}$ I.

33. Lei Federal n..$^{\circ} 1.711$, de 1952, art. 52, n. ${ }^{\circ}$ II.

34. Lei Federal n. ${ }^{\circ} 1.711$, de 1952, art. 52, parág. 1.․ 
importa igualmente alteração do direito ao cargo pela substituição do objeto, o que, ademais, se dá pela promoção, nos cargos que a comportam.

17. Extingue-se o direito ao cargo pela morte do titular (hipótese de fato jurídico a influir na relação jurídica de função pública). Outras formas de extinção são: a) da via administrativa (pena expulsiva, em caso de estabilidade); b) da via judiciária (pena imposta em juízo, em caso de vitaliciedade). Pode-se, contudo, recobrar o direito ao cargo e isto se dá:

a) pela reintegração ${ }^{35}$;

b) pela recondução, isto é, retôrno sem direito a $\operatorname{atrasados}^{36}$ ou readmissão $0^{37}$;

c) reintegração administrativa ${ }^{38}$.

18. A disponibilidade e a aposentadoria não extinguem direito ao cargo; modificam a relação de função pública. A disponibilidade cessa pelo aproveitamento ${ }^{39}$; a aposentadoria pode cessar pela reversão $0^{40}$. Não é exato, entretanto, que a primeira importe suspensão, ou interrupção de "status" e a última fim da relação jurídica, tanto assim que o disponível e o aposentado são subordinados a poder disciplinar ${ }^{41}$.

\section{Defesa do direito ao cargo.}

19. O direito ao cargo, segundo vimos, pode ser golpeado:

35. C. Fed. de 1946: art. 190, Lei Federal n.o 1.711, de 1952, art. 58 .

36. C. Fed. de 1946 , art. 190 , parte final.

37. Lei Federal n..$^{\circ}$ 1.711, de 1952, art. 62.

38. Lei Federal n. ${ }^{\circ}$ 1.711, de 1952, art. 58.

39. Lei Federal n..$^{\circ}$ 1.711, de 1952, art. 64.

40. Lei Federal n. ${ }^{\circ} 1.711$, de 1952 , art. 68.

41. Lei Federal n.o 1.711, de 1952, art. 212 e parágrafo único. 
a) nos casos de estabilidade, pela apuração de culpa disciplinar, ou, pelo procedimento judiciário cuja solução seja perda de cargo público, como pena acessória;

b) nos casos de vitaliciedade, como obediência a determinação de sentença passada em julgado.

Partindo de tais observações, pois, pode-se dizer que a defesa do direito ao cargo:

I) para o estável, ocorre extrajudicialmente: a) no curso do procedimento administrativo disciplinar que tenha por escopo a apuração da culpa disciplinar e subseqüente aplicação de pena expulsiva, por via de ato administrativo punitivo; b) na instância administrativa, através de recursos, inclusive aquêle que objetive a revisão processual; judicialmente, pelo exercício de ação em que tenha em mira sua reintegração, ou pela defesa em juizo criminal para, com a pena principal, obter a exclusão da pena acessória de perda de cargo público ${ }^{42}$;

II) para o vitalício, ocorre, quando, movendo-se-lhe processo, é ameaçado de o perder, por via de determinação judicial.

\section{Observações colhidas da doutrina.}

20. Já se disse aqui que há um direito ao cargo, o qual, não sendo de natureza patrimonial, é, entretanto, de natureza pessoal. Sua conservação verifica-se pelo exercício regular do cargo, através do cumprimento do dever de comparência. (v. I, n. ${ }^{\circ} 4$, retro). Agora se nos oferece ocasião para indagar a maneira por que, em doutrina, se tem entendido êste assunto.

42. Cód. Penal: art. 67, n.o I e art. 70. - Como o faz Borsi, (La giustizia amministrativa, passim), consideramos o Juízo na ação cujo objeto seja administrativo um remédio administrativo, o que aplicamos, ainda ao caso de Jurisdição una, como é o do Brasil. 
21. De uma feita, deixámos, num de nossos escritos, o seguinte: "Aos deveres, em gênero, relativos ao funcionário, correspondem direitos, que a doutrina ora prefere tratar sob a designação de vantagens, ora concede que sejam direitos e vantagens, ou, finalmente, prefere chamar: direitos condicionados, ou mitigados. Não há tempo, nem lugar para que aqui se discutam, na procedência ou improcedência, os fundamentos do que se tem dito a propósito do assunto. Para nós, o de que se trata é de direitos, compreendendo ora um substrato ideal, ora um conteúdo patrimonial. No que concerne à primeira espécie, tem o funcionário direito ao título de que decorre o exercício do cargo público que exerce, bem como às honras a que faz jús em razão dêsse mesmo título. Não tem, porém, direito ao cargo, ainda que seja estável e passada a ratificação do "status" decorrente do estágio probatório. Eis porque, seguindo orientação do Direito Brasileiro e de estatutos anteriores, a Lei Federal . $^{\circ} 1.711$, de 1952, declara no parágrafo $2 .^{\circ}, \mathrm{n}^{\circ}$ II, do artigo 82: “A estabilidade diz respeito ao serviço público e não ao cargo" ${ }^{43}$. Em vista desta afirmativa, fomos honrados com a seguinte crítica: "Entendem alguns que se não pode falar em direito ao cargo em relação aos funcionários estáveis (cf. Fernando H. Mendes de Almeida, ob. cit., p. 181). E os Estatutos procuram adotar essa orientação quando declaram no artigo 82 , parágrafo $20^{\circ}$, que a estabilidade diz respeito ao serviço público e não ao cargo. Essa opinião se origina provàvelmente de que o funcionário estável não goza da inamovibilidade que beneficia os vitalícios. As necessidades do serviço público podem importar na remoção dêle. Mas, ela se fará sempre para cargo equivalente, e jamais para simples função, a que não corresponda tal cargo. A substituição do objeto do direito por outro que proporciona iguais vantagens não demonstra ausência daquele direito, mas,

43. J. H. Mendes DE Almeida, Noções de Direito Administrativo, p. 181, n. ${ }^{\circ} 43$, início. 
sua existência. Por outro lado, se o cargo fôr extinto, ficará o funcionário estável em disponibilidade remunerada até o seu obrigatório aproveitamento em outro cargo de natureza e vencimentos compatíveis com o que ocupava. Por conseguinte, o artigo 82, parágrafo $20^{\circ}$ dos Estatutos contén afirmação que se não compadece com a realidade de outros passos do mesmo diploma"44. Sentimo-nos sobremaneira honrados com a objeção do mestre, em cujo rastilho temos sempre procurado andar. Contudo, como neste estudo passamos a sustentar precisamente a teoria inversa à inspirada pela letra estatutária, não podemos deixar de notar que, na estabilidade, o direito ao cargo não tem tamanha intensidade quanto se apresenta na vitaliciedade, e, sem dúvida, aparece clara aos nossos olhos tal observação, quando notamos que: a) a eliminação dêsse direito, no primeiro caso, é possível apenas por fôrça de procedimento administrativo disciplinar, ao passo que, no segundo, só em razão de sentença passada em julgado; b) a inamovibilidade, implícita na vitaliciedade, ou referida em lei ao lado desta a fim de evitar dúvidas, deixa entrever que o vitalício tem um real direito ao cargo, o que não sucede com o estável, para quem, tal direito não é "ao cargo", mas, " $a$ um cargo", ressalvada apenas a questão da compatibilidade. Poder-se-á dizer, agora, que, a esta altura, nós é que estamos a gizar sutilezas. Não nos enquisilaria a observação, se fôsse procedente. Contudo, ela não o é. E não o é, porque o que dissemos muito pela rama aqui e quanto estamos dizendo ainda, tudo, em suma, foi objeto de discussões na doutrina, lá fora. É o que veremos.

22. Numa lição italiana lê-se: "Perfeita garantia de direito ao cargo é dada ùnicamente àquêles empregados denominados inamoviveis: por isto êsses gozam de tratamento privilegiado em confronto com os demais"45. A

44. Masagão, Curso de Direito Ad., II, p. 231 e 232 , n. 379.

45. VitTa, Diritto Amministrativo, $4 .^{a}$ ed., II, p. 256. 
referência aos que não são inamoviveis e onde se fala em estabilidade $^{46}$ é de que, com tôdas as garantias embora e ao lado das formas de desligação criadas nas leis dos estáveis, não se pode falar tenham "verdadeiro e próprio direito ao cargo"47. É que sòmente se pode falar que ao funcionário cabe um direito subjetivo perfeito ao cargo, quando sua exoneração de ofício e sua demissão ficam subtraídas da apreciação da Administração Pública e entregues a apreciadores a ela estranhos ${ }^{48}$. Aqui, a questão já se resolve em têrmos bem diferentes e são êstes: a) há perfeito direito ao cargo, quanto aos vitalícios, porquanto são inamovíveis e só podem ser demitidos em razão de fatos a serem apreciados por órgãos estranhos à Administração Pública (entre nós: Poder Judiciário); b) há apenas um direito condicionado, quanto aos estáveis, porque êstes podem ser, de um lado, demitidos por fôrça de procedimento administrativo disciplinar, ficando sempre com um interêsse comparável ao interêsse legítimo enquanto não colida com o interêsse público ${ }^{49}$. Portanto, compreendido que o direito ao cargo, nos estáveis, é condicionado, chegaríamos, quiçá à conclusão de que não houve grande evolução da matéria, neste século. Veremos, porém, que tal apreciação é injusta, se voltarmos vistas ao passado, já por via do Direito Positivo, já por via da doutrina, e ali acharmos, ùnicamente, além da vitaliciedade, como exceção, apenas o império do nuto administrativo.

$\mathrm{Na}$ doutrina, entre aquêles que atribuiam à relação de função pública natureza civil, ora falando desta ostensivamente, ora referindo expressões convizinhas, era comum, no passado, negar a existência de direito ao cargo ou fazer-lhe menção. Tal a hipótese da lição que segue: "Convém distinguir a perpetuidade ou estabilidade administrativa da

46. .. "un certo senso di stabilità" (VITTA).

47. VitTA, ob. cit., II, p. 263 e 264.

48. VitTA, ob. cit., II, p. 255.

49. VITTA, ob. cit., II, p. 256. 
estabilidade jurídica, imovibilidade de grau e de cargo" $" 50$. $\mathrm{E}$ depois disto, nada se lê quanto ao direito ao cargo.

Quanto àquêles que resistiam dèbilmente à decisão de convir em que a relação de função pública fôsse de Direito Público e falavam em contrato de "Direito Misto", não faltou, dentre êles, quem, com todo o pêso de sua autoridade, negava o direito ao cargo e ì permanência no serviço público, e, portanto, a estabilidade no sentido próprio e no sentido impróprio ${ }^{51}$.

23. Propendemos realmente - e agora declaramos para adotar esta solução:

I) Quanto a vitalícios, não se pode senão falar em direito ao cargo;

II) quanto a estáveis, o de que se trata é de interêsse tutelado com a variedade que fôr oferecida pela fôrça e pelo fim da norma objetiva reguladora de cada espécie ${ }^{52}$.

\section{O direito ao cargo no Direito Anterior.}

24. No Império, não havia direito ao cargo, no sentido que aqui estamos a examinar. Declarava, efetivamente, a sua Constituição de 25 de março de 1824 que os juízes-dedireito eram "perpétuos", porém, amovíveis ${ }^{53}$ porque mutáveis "de uns para outros lugares pelo tempo e maneira que a lei determinar" 54 . Contudo, sòmente poderiam

50. MeuccI, Istituzioni di Diritto Amministrativo, 6. ${ }^{\mathrm{a}}$ ed., 1909, p. 210.

51. Orlando, Principi di Diritto Amministrativo, p. 125 a 128, n. ${ }^{\circ}$ s. 194 a 200, da 5. ${ }^{a}$ ed., 1925. No mesmo sentido: Principi di Diritto Amministrativo, p. 108 e 109 de Romano; Presutti, Istituzioni di Diritto Amministrativo Italiano, II, 1905, p. 11 e 12, n. 415.

52. Petrozalello, ob. cit., p. 236; LentinI, Istituzioni di Diritto Amministrativo, I, p. 572.

53. Const. do Império: Art. 153.

54. Const. do Império: Art. 153. 
"perder seus lugares por sentença" 55 , ainda que o Imperador os pudesse suspender, depois de ouvi-los, tomada audiência do Conselho de Estado em sede jurisdicional ${ }^{56}$. Ora, se o atributo da inamovibilidade, que deve estar implícito na vitaliciedade, não existe, de nada vale falar em "perpetuidade" 57 . Por isso é que, segundo nos parece, é lícito concluir que nem os juízes de direito foram, no Império, titulares de direito perfeito ao cargo. Quanto aos funcionários no sentido restrito, não se cuidava senão de pô-los sob o grifo comum da chamada: "demissibilidade ad nutum". Limitava-se a Constituição Imperial a proclamar que todo cidadão poderia ser admitido aos cargos públicos, "sem outra diferença que não a de seus talentos e virtudes" "58. E as leis ordinárias, ao demais, nada mais disseram quanto a qualquer vislumbre de estabilidade.

25. Por igual, nem a sempiterna e inolvidável porque a maior, pela técnica, isto é, a Constituição Federal de 1891, cuidou da estabilidade. A vitaliciedade, porém, nela, mereceu carinhosa preceituação ${ }^{59}$ e, sob a sua vigência, a jurisprudência do Supremo Tribunal Federal e leis federais ordinárias construiram as bases do que, ao depois, se chamou: estabilidade ${ }^{60}$. Como se formou, històricamente, a idéia de estabilidade tal qual vemos, no Direito Brasileiro, é ponto para rememorar aqui.

55. Const. do Império: Art. 155.

56. Const. do Império: Art. 154. - O Conselho do Estado era o órgão básico do contencioso administrativo que existiu no Império. Fci extinto pelo artigo 32 do Ato Adicional (Lei de 12 de agôsto de 1834), mas, recriado, não só como órgão consultivo, pela Lei Ordinária n. ${ }^{\circ} 234$, de 23 de novembro de 1841.

57. Const. do Império: art. 153.

58. Const. do Império: art. 179, n. ${ }^{\circ} 14$.

59. Const. Fed. de 1891: art. 57 e art. 89, parte final.

60. Util é, a êste propósito, a leitura dos segs. trabalhos: PeDro Lessa, Do Poder Judiciário; Paulo Domingues Vianna, Do estatuto dos funcionários públicos. RUI BARBOSA, Razões em defesa do Dr. Baptista Pereira. 
$\mathrm{O}$ artigo $9 .^{\circ}$ da Lei Federal n. ${ }^{\circ}$ 141-B de 30 de outubro de 1893 já acenava para um certo alargamento do âmbito da vitaliciedade, quando dispusera que os empregados de concurso sòmente poderiam ser demitidos em virtude de sentença e o Supremo Tribunal Federal, com jurisprudência oscilante embora, ia entendendo que a cláusula "enquanto bem servir", pôsto não envolvesse vitaliciedade, exigia apuração de fatos e momentos em que aquêle que fôsse alvo de demissão tivesse começado a mal servir. Caso típico em que se assinalou tal evolução é o que iremos resumir, em seguida.

26. Por decreto de 16 de julho de 1907 foi demitido um médico do internato do "Colégio Pedro II". Imputara-se-lhe desídia em nota confidencial do Diretor do estabelecimento ao Ministro da Justiça e dos Negócios do Interior e, êste, sem ouvi-lo, demitiu-o. Demitido, contudo, não se conformou, porque, sôbre não ter sido ouvido de qualquer modo quanto à imputação que se lhe fizera, fôra admitido sob a cláusula "enquanto bem servir". E judicialmente logrou ver coroada de êxito sua pretensão de reintegrar-se ${ }^{61}$. É que a cláusula era tradução do "during good behaviour" com que eram nomeados os juízes da Suprema Côrte Americana, os quais, embora não vifalícios, para que fôssem demitidos, só poderiam sê-lo com ficar provado quando e como começaram a mal servir ${ }^{62}$. Êste e outros julgados de solução análoga, a despeito da oscilação da jurisprudência, acrescidos da circunstância de a Lei Federal n..$^{\circ} 117$, de 4 de novembro de 1892 haver previsto aposentadoria num sistema em que a chamada demissibilidade "ad nutum" era regra, levaram o legislador federal a baixar um diploma em que se esquematizou a estabilidade, consagrada, ao depois, em texto

61. Paulo Domingues Vianna, Do estatuto dos func. públicos, p. 48 a 52 .

62. Veja-se também Rui Barbosa, Demissão de Curador de Orfãos, p. 59. Em sentido oposto: ARAujo CASTRo, Estabilidade de funcionários públicos, p. 88 . 
constitucional ${ }^{63}$. Foi a Lei Federal $n .^{0} 2.924$, de 5 de janeiro de 1915 que, no seu texto, declarou: "O funcionário ... federal, salvo ... em comissão, que contar 10 ou mais anos de serviço federal sem ter sofrido pena no cumprimento de seus deveres, só poderá ser destituido, ... mediante processo administrativo". Foi dai que os constituintes de 1933 colheram elementos para a redação (aliás, infelicíssima) do artigo 169 da Constituição Federal de 16 de julho de 1934. De qualquer modo, deve ficar bem claro que a história da estabilidade na relação jurídica da função pública é efeito de 4 causas:

a) a jurisprudência do Supremo Tribunal Federal;

b) a aposentadoria ampliada, constante da Lei Federaj n. ${ }^{\circ} 117$, de 4 de novembro de 1892;

c) a Lei Federal n. 2.294 de 5 de janeiro de 1915;

d) a canonização constitucional ocorrida no artigo 169 da Constituição Federal de 1934 mantida pela Carta Constitucional de 10 de novembro de 1937, no artigo 156, letra "c" e, finalmente, no artigo 189, pela Constituição Federal vigente ${ }^{63}$, onde as idéias ficaram, a final, satisfatòriamente $\operatorname{claras}^{64}$.

63. Tanto o argumento da aposentadoria conta, na história, que - Supremo Tribunal ("O Direito", vol. 104, p. 512; Alcides Cruz, Direito Administrativo, 2. ${ }^{\mathrm{a}}$ ed. p. 96), entendia que o aposentado se transformava em vitalício, qualquer que fôsse a natureza da relação de função públiea na atividade.

64. Para um histórica mais rico, leiam-se: Pedro Lessa, Do Poder Judiciáio, p. 32 e segs. RoDRIGo OCTÁvio, Pareceres na Consultoria Geral da República, parecer 79-A, de 22 de julho de 1914; THEMÍsTocles Brandão Cavalcanti, Instituições de Direito Administrativo Brasileiro, 1936 , p. 565 e 570.

65. No Acórdãa no Recurso da Segurança n. 9.593, (Rev. de Direito Administrativo, vol. 70, p. 170). Ministro GALlOTTI diferença "efetividade" e "estabilidade", dando a primeira como um estado preparatório para a segunda, em vista do disposto no art. 188 da C. Fed. de 1946. Respeitamos, mas, não esposamos sua opinião pessoal. 